\title{
The intubating laryngeal mask airway in severe ankylosing spondylitis
}

\section{[L'utilisation du masque laryngé d'intubation en cas de spondylarthrite ankylosante sévère]}

Pao-Ping Lu MD, ${ }^{*}$ Joseph Brimacombe MB CHB FrCA MD, $\dagger$ Angie C.Y. Ho MD, ${ }^{*}$ Ming-Hwang Shyr MD PhD, ${ }^{*}$ Hung-Pin Liu MD*

Purpose: To evaluate the use of inhalational induction followed by intubation through the intubating laryngeal mask (ILM) for patients with severe ankylosing spondylitis undergoing elective surgery who prefer airway management under anesthesia.

Methods: Nine patients undergoing a total of II procedures were enrolled in the study. Fentanyl $2 \mu \mathrm{g} \cdot \mathrm{kg}^{-1}$, midazolam $0.035 \mathrm{mg} \cdot \mathrm{kg}^{-1}$ and sevoflurane in oxygen 100\% were used for induction. The ILM was inserted when the end-tidal sevoflurane concentration reached $3 \%$. After an effective airway was established, atracurium 0.5 $\mathrm{mg} \cdot \mathrm{kg}^{-1}$ was given. A polyvinyl chloride tube in the reversed position using a blind technique was used to intubate the trachea.

Results: The ILM provided an effective airway on I I/I I occasions at the first attempt. Intubation was successful at the first attempt on $7 / I I$ occasions, at the second attempt on $2 / 11$ and at the third attempt in $\mathrm{I} / \mathrm{I} \mathrm{I}$. Intubation failed in one patient. The mean (range) minimal oxygen saturation was $99.4 \%$ (97-100\%). There were no problems with ILM removal.

Conclusion: Inhalational induction followed by ILM insertion and blind intubation is a reasonable option in patients with severe ankylosing spondylitis undergoing elective surgery who prefer airway management under anesthesia.

Objectif : Évaluer l'utilisation de l'induction par inhalation suivie de l'intubation au travers du masque laryngé d'intubation (MLI) chez des patients qui présentent une spondylarthrite ankylosante sévère, qui doivent subir une intervention non urgente, mais qui préferent une intubation sous anesthésie.

Méthode : Neuf patients, admis pour I I interventions au total, ont été recrutés pour participer à l'étude. On a utilisé $2 \mu \mathrm{g} \cdot \mathrm{kg}^{-1}$ de fentanyl, $0,035 \mathrm{mg} \cdot \mathrm{kg}^{-1}$ de midazolam et du sévoflurane dans de l'oxygène à 100 \% pour l'induction anesthésique. On a ensuite inséré le MLI quand la concentration de sévoflurane de fin d'expiration a atteint 3 $\%$. Après avoir assurer la liberté des voies respiratoires, on a admi- nistré $0,5 \mathrm{mg} \cdot \mathrm{kg}^{-1}$ d'atracurium. On a utilisé un tube endotrachéal de chlorure de polyvinyle en position renversée pour réaliser l'intubation endotrachéale à l'aveugle.

Résultats : Le MLI a permis une perméabilité efficace des voies aériennes I I/I I fois au premier essai. L'intubation a été réussie au premier essai dans $7 / 1 /$ cas, au second essai dans $2 / 1 /$ cas et au troisième, dans un cas. L'intubation a été un échec chez un patient. La saturation minimale moyenne en oxygène (intervalle) a été de 99,4\% (97-100\%). Le MLI a été retiré sans difficulté.

Conclusion : L'induction par inhalation suivie de l'insertion d'un MLI et d'une intubation à l'aveugle apparait comme une option possible chez des patients atteints de spondylarthrite ankylosante sévère qui préferent une intubation sous anesthésie.

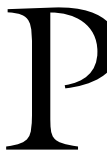

ATIENTS with severe ankylosing spondylitis (AS) are frequently difficult or impossible to intubate due to limited mouth opening and/or cervical spine rigidity. Awake fibreoptic intubation is probably the safest option, but some patients refuse awake intubation ${ }^{1}$ and on occasions it can fail. ${ }^{2}$ The classic laryngeal mask airway (LMA) and/or intubating laryngeal mask (ILM) airway devices have been used anecdotally in AS patients following failed laryngoscope-guided tracheal intubation, ${ }^{3-5}$ for awake insertion, ${ }^{2,6}$ and as an alternative to, ${ }^{1}$ and/or aid to $^{7}$ tracheal intubation in anesthetized patients, but there are no published data about success rates in any of these situations. We evaluate the use of inhalational induction with sevoflurane followed by intubation through the ILM for management of patients with severe AS undergoing elective surgery who prefer airway management under anesthesia.

From the Department of Anesthesia, ${ }^{*}$ Chang Gung Memorial Hospital, Taoyuan Hsien, and the Department of Anesthesia and Intensive Care, $\nmid$ University of Queensland, Cairns Base Hospital, Cairns, Australia.

Address correspondence to: Dr. Joseph Brimacombe, Department of Anesthesia and Intensive Care, University of Queensland, Cairns Base Hospital, The Esplanade, Cairns 4870, Australia. Phone: 61-7-40-506960; Fax: 61-7-40-506854; E-mail:

jbrimacombe@austarnet.com.au

Accepted for publication April 2, 2001.

Revision accepted July 11, 2001. 


\section{Methods}

After Ethics Committee approval and written informed consent, we prospectively studied patients with severe AS presenting for elective surgery over a 12 -month period (April 1999 - March 2000) who preferred airway management under general anesthesia. Patients were excluded if they had oropharyngolaryngeal pathology, an interdental gap $<2 \mathrm{~cm}$, or if they were judged to be at risk of aspiration (not fasted, previous upper gastrointestinal tract surgery, known or symptomatic hiatus hernia, esophageal reflux, peptic ulceration).

A standard anesthesia protocol was followed and routine monitoring applied. Patients were in the supine position with the head and neck supported on pillows so that they were as close to the neutral position as possible within their comfort range. Patients were given $2 \mu \mathrm{\mu g} \cdot \mathrm{kg}^{-1}$ fentanyl and $0.035 \mathrm{mg} \cdot \mathrm{kg}^{-1}$ midazolam and underwent inhalational induction by breathing sevoflurane, spontaneously and unassisted, in $100 \%$ oxygen delivered via a face mask. When the eyelash reflex disappeared, the jaw relaxed and the end-tidal sevoflurane concentration was $3 \%$, the ILM was inserted using a single handed rotational technique. The size 4 ILM was used for males $75 \mathrm{~kg}$ and the size 3 for women and males $<75 \mathrm{~kg}$. The cuff was inflated to an intracuff pressure of $60 \mathrm{~cm} \mathrm{H}_{2} \mathrm{O}$ using a cuff inflator-manometer and manually assisted ventilation commenced. If an effective airway was not obtained, the position of the ILM was adjusted by moving the cuff up, down, to the right or left, as judged by the operator. If ventilation was still ineffective after these adjustments, the ILM was removed and either the same size or a larger size inserted, as judged by the operator. An effective airway was judged by a square wave capnograph trace and no audible leak with peak airway pressures $15 \mathrm{~cm} \mathrm{H}_{2} \mathrm{O}$ during gentle manual ventilation. A maximum of three ILM insertions was permitted. Once an effective

TABLE Summary of cases where the classic or intubating laryngeal mask airway has been used in patients with ankylosing spondylitis

\begin{tabular}{|c|c|c|c|c|c|c|}
\hline Authors & Device & $\begin{array}{l}\text { No of } \\
\text { cases }\end{array}$ & $\begin{array}{l}\text { Insertion } \\
\text { awake or } G A\end{array}$ & $\begin{array}{l}\text { Intubation } \\
\text { yes/no }\end{array}$ & Airway Scenario & Notes \\
\hline Chadd et al. ${ }^{7}$ & LMA & 1 & GA & Yes & Planned use & $\begin{array}{l}\text { Intubated via LMA with } \\
\text { bougie }\end{array}$ \\
\hline $\begin{array}{l}\text { Williams and } \\
\text { Bailey }^{2}\end{array}$ & LMA & l & Awake & No & $\begin{array}{l}\text { After failed awake } \\
\text { fibreoptic intubation }\end{array}$ & $\begin{array}{l}\text { Induction after successful } \\
\text { awake insertion }\end{array}$ \\
\hline Steib et $a l^{3}$ & LMA & 1 & GA & Yes & $\begin{array}{l}\text { After failed laryngoscope- } \\
\text { guided intubation }\end{array}$ & $\begin{array}{l}\text { Blind intubation failed, but } \\
\text { FOS successful } \\
\text { Developed transient 12th }\end{array}$ \\
\hline King and Street ${ }^{17}$ & LMA & 1 & GA & No & Planned use & cranial nerve palsy \\
\hline Smigovec et al. ${ }^{18}$ & LMA & 2 & GA & No & $\begin{array}{l}\text { After failed laryngoscope- } \\
\text { guided intubation }\end{array}$ & Successful insertion \\
\hline Aziz et al. ${ }^{11 *}$ & LMA & 1 & GA & No & Planned use & $\begin{array}{l}\text { Failed placement due to } \\
\text { cervical osteophytes }\end{array}$ \\
\hline Jun et al. ${ }^{4}$ & LMA & 1 & GA & Yes & Planned use & $\begin{array}{l}\text { Intubated via LMA with } \\
\text { FOS }\end{array}$ \\
\hline Defalque and Hyder ${ }^{1}$ & LMA & 1 & GA & No & Planned use & Successful insertion \\
\hline Pothmann et al. ${ }^{19}$ & LMA & 1 & GA & No & $\begin{array}{l}\text { After failed laryngoscope- } \\
\text { guided intubation }\end{array}$ & Successful insertion \\
\hline Kinorons and Dwyer ${ }^{20}$ & LMA & 1 & GA & Yes & Planned use & $\begin{array}{l}\text { Intubated via LMA with } \\
\text { bougie }\end{array}$ \\
\hline Wallace and Chung ${ }^{5}$ & LMA & 1 & GA & No & $\begin{array}{l}\text { After failed seal - saber } \\
\text { sheath trachea }\end{array}$ & Successful insertion \\
\hline Dimitriou et al. ${ }^{6}$ & ILM & 1 & Awake & Yes & Planned use & $\begin{array}{l}\text { Successful insertion and } \\
\text { lightwand guided intubation }\end{array}$ \\
\hline
\end{tabular}

* $=$ ankylosing vertebral hyperostosis (Forestier's disease). ${ }^{2}$

GA=general anesthesia; LMA=laryngeal mask airway; ILM=intubating laryngeal mask airway; FOS=fibreoptic scope. 


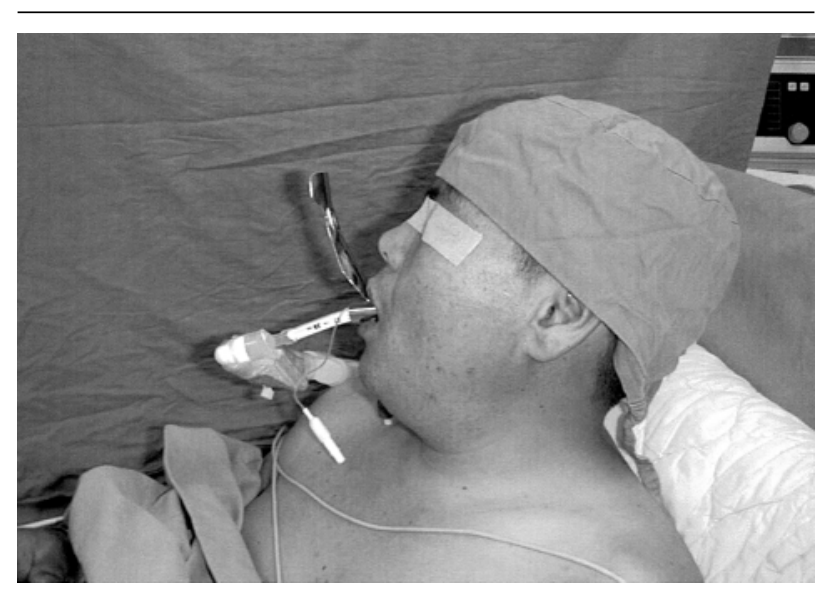

FIGURE: Patient with severe ankylosing spondylitis requiring intubation in the sitting position.

airway was obtained, the position of the ILM was further adjusted by moving the cuff within the pharynx until the best seal was obtained, as judged by maximal chest expansion without an oropharyngeal air leak. Patients were then paralyzed with atracurium 0.5 $\mathrm{mg} \cdot \mathrm{kg}^{-1}$ and blind intubation attempted using a welllubricated $7.0 \mathrm{~mm}$ polyvinyl chloride tracheal tube (Sheridan ${ }^{\circledR}$ tracheal tube, The Kendall Company, USA) inserted in the reversed position. ${ }^{8}$ Bilateral breath sounds and a square wave capnograph trace confirmed successful tracheal intubation. If resistance was encountered or esophageal intubation occurred (no resistance to insertion and no capnograph trace), the position of the ILM was adjusted by moving the cuff up, down, to the right or left before the next intubation attempt, as judged by the operator. A maximum of three intubation attempts was permitted Once intubation was accomplished, the ILM was removed using an extender. One of the authors (P.L.), with prior experience of 100 uses of the ILM, performed all insertions and intubations.

The following data were collected: the number of insertion and intubation attempts; heart rate and mean blood pressure pre-induction, one minute after successful ILM insertion and one minute after successful intubation; and minimal oxygen saturation occurring between induction and one minute after intubation. The next day patients were questioned about their experience and sore throat. Hemodynamic data were compared using one-way analysis of variance. Significance was taken as $P<0.05$.

\section{Results}

Nine patients were included in the study and two patients had two procedures. The mean (range) age and weight was $55(37-75) \mathrm{yr}$ and $69(50-107) \mathrm{kg}$ respectively. The male:female ratio was $6: 3$. Eight patients had a greater than $20-\mathrm{yr}$ history of AS and one patient had a greater than ten-year history. All patients had limited atlanto-occipital joint extension with cervical spine mobility less than 90, judged clinically. One patient had a thoracic spine kyphosis and intubation was performed in the sitting position (Figure). Four patients had not been previously anesthetized, three had a history of difficult intubation and two had been intubated four and seven years previously. There were no episodes of loss of airway control during inhalational induction. The ILM provided an effective ventilatory device on $11 / 11$ occasions at the first attempt. Intubation was successful at the first attempt on $7 / 11$ occasions, at the second attempt on $2 / 11$ and at the third attempt in $1 / 11$. Success at the second and third attempts was accomplished by positional changes to the ILM. Intubation failed in one patient. Fibreoptic inspection revealed that this was due to a large downfolded epiglottis that was not displaced by the epiglottic elevating bar and could not be corrected by positional changes. No esophageal intubation occurred. Mean blood pressure was higher after intubation than after ILM insertion (mean \pm SD: $103 \pm 14$ vs $82 \pm 15 \mathrm{mmHg}, P=0.01$ ), but did not differ from baseline values $(95 \pm 17 \mathrm{mmHg})$. Heart rate was similar after intubation $\left(85 \pm 14\right.$ beats $\left.\cdot \mathrm{min}^{-1}\right)$ and ILM insertion $\left(80 \pm 13\right.$ beats $\left.\cdot \mathrm{min}^{-1}\right)$ and did not differ significantly from baseline values $(70 \pm 15$ beats. $\min ^{-1}$ ). The mean (range) minimal oxygen saturation was $99.4 \%(97-100 \%)$. There were no problems with ILM removal. All patients were content with the anesthetic technique. Two patients complained of a sore throat.

\section{Discussion}

Our data suggests that inhalational induction with sevoflurane followed by intubation through the ILM is a reasonable option for patients with AS who refuse awake intubation. There have been 12 cases of the LMA or ILM being used in patients with AS (Table). Insertion failed in only one of these cases. The advantages of the LMA or ILM for AS are that insertion and intubation can be accomplished without head and neck movement or direct laryngoscopy, and ventilation can continue during intubation. The limitations of the LMA or ILM are that insertion may be difficult if mouth opening is limited $\left(<1.2 \mathrm{~cm}^{9}\right.$ for LMA; $<2$ $\mathrm{cm}$ for $\mathrm{ILM}^{10}$ ), if large cervical osteophytes are pre- 
sent ${ }^{11}$ or if the patient has a fixed extension deformity. ${ }^{12}$ The ILM offers potential advantages over the LMA in patients with AS since it may be easier to insert in a patient with an immobile neck ${ }^{13}$ and the ILM is a better airway intubator. ${ }^{14}$ However, the LMA would be more suitable if mouth opening was less than $2 \mathrm{~cm}$ or intubation was not required. Our finding that blood pressure was higher after intubation through the ILM than after ILM insertion matches the findings of Kihara et al. ${ }^{15}$ for normal patients.

We induced anesthesia with sevoflurane to minimize the risk of sudden loss of airway control. There have been several studies reporting LMA insertion following induction with sevoflurane but, to our knowledge, this is the first report of ILM insertion following sevoflurane induction. We administered muscle relaxants only when effective ventilation was established and used them to facilitate intubation. Interestingly, muscle relaxation is not necessary for successful intubation through the ILM provided depth of anesthesia is adequate. ${ }^{16}$ We used a precurved PVC tracheal tube rather than the straight silicone tube because precurved PVC tubes are more readily available and have a high success rate and low complication rate when inserted with the curve in the reverse direction. ${ }^{8}$ In AS patients with crico-arytenoid disease the softer tip and midline bevel of the straight silicone tube might reduce the risk of trauma. We attempted intubation using a blind rather than a fibreoptic-guided technique to simulate conditions when fibreoptic equipment is unavailable. However, we recommend that, whenever possible, a fibreoptic technique is used since success rates will probably be higher and the risk of trauma lower.

We conclude that inhalational induction followed by ILM insertion and blind intubation is a reasonable option in patients with severe ankylosing spondylitis undergoing elective surgery who prefer airway management under anesthesia.

\section{References}

1 Defalque RJ, Hyder ML. Laryngeal mask airway in severe cervical ankylosis. Can J Anaesth 1997; 44: 305-7.

2 Williams PJ, Bailey PM. Management of failed ora fibreoptic intubation with laryngeal mask airway insertion under topical anaesthesia (Letter). Can J Anaesth 1993; 40: 287

3 Steib A, Beller JP, Llen JC, Otteni JC. Difficult intubation managed by laryngeal mask and fibroscopy (French). Ann Fr Anesth Reanim 1992; 11: 601-3.

4 Jun JH, Seung IS, Cho SY, Sub JK. Laryngeal mask airway - endotracheal intubation with laryngeal mask air- way and fibreoptic bronchoscope. J Kor Soc Anesthesiol 1993; 26: 1029-34

5 Wallace EJ, Chung F. General anesthesia in a patient with an enlarged saber sheath trachea. Anesthesiology 1998; 88: 527-9.

6 Dimitriou V, Voyagis G, Brimacombe J. Flexible lightwand-guided intubation through the ILM (Letter). Acta Anaesthesiol Scand 2001; 45: 263-4.

7 Chadd GD, Ackers JWL, Bailey PM. Difficult intubation aided by the laryngeal mask airway (Letter). Anaesthesia 1989; 44: 1015.

8 Lu P-P, Yang C-H, Ho ACY, Shyr $M-H$. The intubating LMA: a comparison of insertion techniques with conventional tracheal tubes. Can J Anesth 2000; 47: $849-53$.

9 Maltby JR, Loken RG, Beriault MT, Archer DP. Laryngeal mask airway with mouth opening less than 20 mm. Can J Anaesth 1995; 42: 1140-2.

10 Brimacombe J, Keller C, Weidmann K. Limited mouth opening and the intubating laryngeal mask (Letter). Can J Anaesth 1999; 46: 807-8.

11 Aziz ES, Thompson AR, Baer S. Difficult laryngeal mask insertion in a patient with Forestier's disease (Letter). Anaesthesia 1995; 50: 370

12 Ishimura H, Minami K, Sata T, Shigematsu A, Kadoya $T$. Impossible insertion of the laryngeal mask airway and oropharyngeal axes. Anesthesiology 1995; 83: 867-9.

13 Asai T, Wagle AU, Stacey M. Placement of the intubating laryngeal mask is easier than the laryngeal mask during manual in-line neck stabilization. Br J Anaesth 1999; 82: 712-4.

14 Lucas DN, Yentis SM. A comparison of the intubating laryngeal mask tracheal tube with a standard tracheal tube for fibreoptic intubation. Anaesthesia 2000; 55: 358-61.

15 Kibara S, Watanabe S, Taguchi N, Suga A, Brimacombe $J R$. Tracheal intubation with the Macintosh laryngoscope versus intubating laryngeal mask airway in adults with normal airways. Anaesth Intens Care 2000; 28: 281-6.

16 Rocchiccioli C, Blumen M, Chabolle F, Fischler M. Successful use of LMA Fastrach ${ }^{\mathrm{TM}}(\mathrm{FT})$ in patients with obstructive sleep apnea syndrome and predictive signs of difficult airway. Anesthesiology 2000; 93: Al112 (abstract).

17 King C, Street MK. Twelfth cranial nerve paralysis following use of a laryngeal mask airway. Anaesthesia 1994; 49: 786-7.

18 Smigovec E, Sakic K, Tripkovic B. The laryngeal masknews in orthopedic anesthesia (Roman). Lijec Vjesn 1993; 115: 166-9.

19 Pothmann W, Eckert S, Fullekrug B. Use of the laryngeal mask in difficult intubation (German). Anaesthesist 1993; 42: 644-7. 
20 Kinirons $B$, Dwyer $R$. Renal transplantation in a patient with ankylosing spondylitis. Br J Hosp Med 1996; 56: 298.

21 Forestier J, Rotes Querol J. Senile ankylosing hyperostosis of the spine. Annals of Rheumatic Disease 1950; 9 : 321-30.

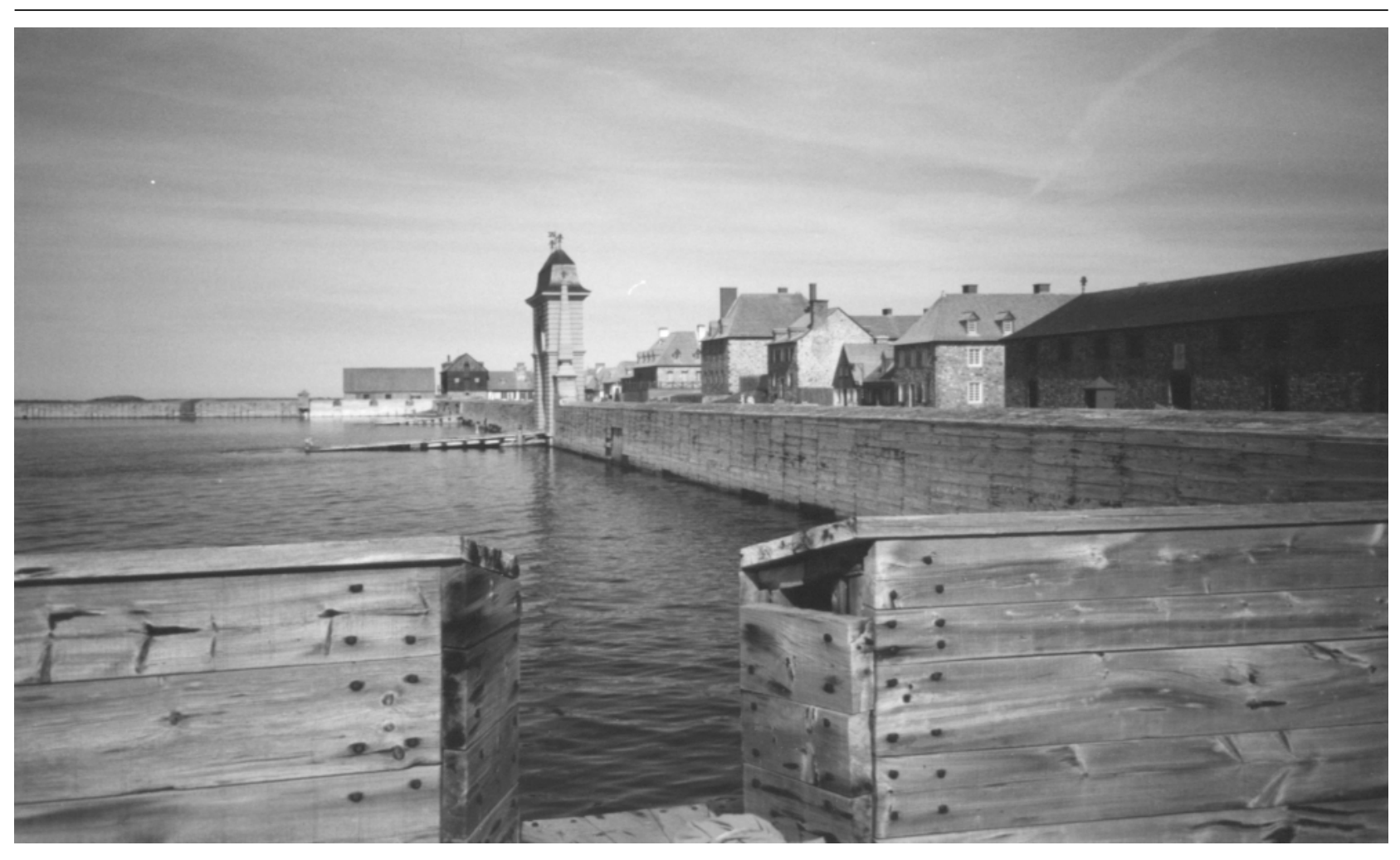

Forteresse de Louisbourg - Nova Scotia 